Check for updates

Cite this: RSC Adv., 2018, 8, 7269

Received 20th November 2017 Accepted 31st January 2018

DOI: 10.1039/c7ra12615h

rsc.li/rsc-advances

\section{Synthesis of different crystallographic FeOOH catalysts for peroxymonosulfate activation towards organic matter degradation $\uparrow$}

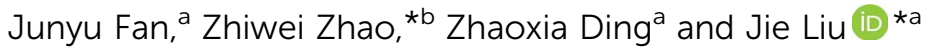

In this study, different crystalline structures of $\mathrm{FeOOH}$ have been prepared. $\alpha$-FeOOH was synthesized through a hydrothermal method, whereas $\beta-\mathrm{FeOOH}$ was synthesized via a direct hydrolysis method. Moreover, $\gamma$ - and $\delta$-FeOOH were prepared by precipitation methods through slow and quick oxidation, respectively. On this basis, their crystal structure, morphology, and surface area were measured. Then, all the synthesized materials were applied to activate peroxymonosulfate (PMS) to generate sulfate radicals $\left(\mathrm{SO}_{4}{ }^{-}\right.$) for acid orange 7(AO7) degradation. Compared with $\alpha-\mathrm{FeOOH}, \beta-\mathrm{FeOOH}$, and $\gamma-\mathrm{FeOOH}, \delta-$ $\mathrm{FeOOH}$ showed more efficient decolorization of $\mathrm{AO} 7$ in the catalytic system because of its abundant surface area and crystalline structure. The effects of several parameters in the $\delta$-FeOOH/PMS/AO7 system were investigated. The results show that the initial $\mathrm{pH}$, which is related to the features of surface hydroxyl groups, is the decisive factor, and excellent catalytic activity is maintained in the pH range 5-8. The increase of catalyst dosage and appropriate increase of PMS concentration contributed to promote the degradation effect. However, self-quenching was observed in a high PMS concentration system. Moreover, $\delta$-FeOOH was stable after six consecutive cycles, and the leaching of iron ions was negligible. According to the quenching test and electron spin resonance analysis, both $\mathrm{SO}_{4}{ }^{-} \cdot$ and ${ }^{\circ} \mathrm{OH}$ were the dominant radicals for $\mathrm{AO}$ degradation.
\end{abstract}

\section{Introduction}

In recent years, it has been proven that the radicals produced by the advanced oxidation process (AOP) can effectively attack the chromophoric group of the dye and make the dye mineralize completely. The common radicals used in wastewater treatment are hydroxyl radical ( $\left.{ }^{\circ} \mathrm{OH}\right)$ and sulfate radical $\left(\mathrm{SO}_{4}{ }^{-\cdot}\right)$.

The Fenton method, which relies on the hydroxyl radical, is the most widely used AOP. Compared to the traditional homogeneous Fenton method, heterogeneous Fenton method is more popular because it does not cause secondary pollution. Among all kinds of heterogeneous Fenton catalysts, iron-based materials, including $\mathrm{Fe}_{2} \mathrm{O}_{3},{ }^{1} \mathrm{Fe}_{3} \mathrm{O}_{4},{ }^{2} \mathrm{MnFe}_{2} \mathrm{O}_{4},{ }^{3}$ and $\mathrm{FeOOH},{ }^{4}$ have always been the focus due to their wide sources, high performance, and low cost.

As an eco-friendly iron-based material with different crystalline structures $(\alpha-, \beta-, \gamma-$, and $\delta$-), hydroxyl iron oxide ( $\mathrm{FeOOH})$ has been reported to be used in different heterogeneous

${ }^{a}$ Department of Military Facilities, Army Logistics University, Chongqing, 401311, China. E-mail: liujiely@hotmail.com; Tel: +862386730631

${ }^{b}$ Key Laboratory of the Three Gorges Reservoir Region's Eco-Environment, State Ministry of Education, Chongqing University, Chongqing, 400045, China. E-mail: zhaozhiweihit@gmail.com

$\dagger$ Electronic supplementary information (ESI) available. See DOI: $10.1039 / \mathrm{c} 7 \mathrm{ra} 12615 \mathrm{~h}$ catalysis systems to remove dyes and other refractory contaminants from aqueous solutions. Silva et al. used $\delta$ - $\mathrm{FeOOH}$ as a catalyst to degrade rhodamine $\mathrm{B}$ in a photo-Fenton system. ${ }^{5}$ Wang et al. explored the activation effect of $\mathrm{H}_{2} \mathrm{O}_{2}$ to remove phenol by $\alpha-\mathrm{FeOOH} / \mathrm{rGO}$ composite materials. ${ }^{6}$ Zhang et al. prepared SBC@ß-FeOOH composites in a heterogeneous Fenton-like reaction to remove doxycycline. ${ }^{7}$ Sheydaei et al. made reactive orange 29 as the target pollutant to explore the sonocatalytic decolorization of textile wastewater by $\gamma$-FeOOH nanoparticles. ${ }^{8}$ Moreover, FeOOH could effectively promote the generation of ${ }^{\circ} \mathrm{OH}$ in the presence of ozone. ${ }^{9}$

The sulfate radical mainly obtained by activating peroxymonosulfate and persulfate has the great advantage of its stabile oxidation reduction potential $(2.01 \mathrm{eV}$ at $\mathrm{pH} 7$ and $1.96 \mathrm{eV}$ at $\mathrm{pH} 4){ }^{10-12}$ Unlike persulfate, which requires other auxiliary methods (ultraviolet, ultrasound, and microwave), peroxymonosulfate (PMS) is more easily activated in a heterogeneous system in a neutral medium, especially by iron-based catalysts such as $\alpha-\mathrm{Fe}_{2} \mathrm{O}_{3},{ }^{13,14} \quad \mathrm{Fe}_{3} \mathrm{O}_{4},{ }^{14,15} \mathrm{MnFe}_{2} \mathrm{O}_{4},{ }^{16}$ and $\mathrm{Fe}(0) \cdot{ }^{17}$ However, no study has been reported on the activation of PMS with $\mathrm{FeOOH}$ to produce a sulfate radical. On the other hand, based on the existing literature, there are differences in the efficiencies of degradation when FeOOH with different structures is used. ${ }^{5,8}$ However, the influence of their different crystal structures on the degradation process has been rarely analyzed in detail. 
In the present study, FeOOH nanoparticles with different crystal structures $\left(\alpha-, \beta-, \gamma^{-}\right.$, and $\delta$-) were synthesized and characterized. Then, the obtained solids were used as PMS activators for the first time to degrade acid orange 7 (AO7), a carcinogenic azo dye. After the activation effect was estimated, the catalytic mechanism was proposed according to the results.

\section{Experimental}

\subsection{Materials}

Ferric nitrate $\left(\mathrm{Fe}\left(\mathrm{NO}_{3}\right)_{3} \cdot 9 \mathrm{H}_{2} \mathrm{O}\right)$, ferrous sulfate $\left(\mathrm{FeSO}_{4} \cdot 7 \mathrm{H}_{2} \mathrm{O}\right)$, polyvinylpyrrolidone (PVP K30), ethylenediaminetetraacetic acid disodium salt (EDTA), urea, hydrochloric acid ( $\mathrm{HCl}$ ), sodium hydroxide $(\mathrm{NaOH})$, hydrogen peroxide solution $(30 \%)$, and ammonia solution (30\%) were purchased from Sinopharm Chemical Reagent Co., Ltd (Shanghai China). Acid orange 7 (AO7) anhydrous ethanol, tertiary butyl alcohol (TBA), and oxone (PMS, $\mathrm{KHSO}_{5} \cdot 0.5 \mathrm{KHSO}_{4} \cdot 0.5 \mathrm{~K}_{2} \mathrm{SO}_{4}$ ) were purchased from Aladdin Industrial Co. Ltd. (Shanghai, China). All the solutions were prepared with deionized water.

\subsection{Synthesis of catalysts}

Preparation of all the crystal structures of catalysts was directly adopted from previously reported methods. The schematic of the preparation of each crystal type of FeOOH is shown on Fig. 1, and the detailed synthesis methods have been described hereinafter.

2.2.1. Synthesis of the $\alpha$-FeOOH catalyst. $\alpha-\mathrm{FeOOH}$ can be synthesized from either Fe(III) or Fe(II) systems. Due to the need for careful control to prevent other oxidation products for $\mathrm{Fe}$ (II) systems, the Fe(III) system is recommended. In the Fe(III) system, $\alpha$-FeOOH can be formed over a wide $\mathrm{pH}$ range, either in acidic or alkaline media. ${ }^{18}$ Because of the rapid formation of precipitates in the alkaline media, it is generally used. In the alkaline media, synthesis involves holding freshly prepared ferrihydrite, which is the precursor of $\alpha-\mathrm{FeOOH}$, at $\mathrm{pH}>12$ for several days. ${ }^{18}$ Recently, to decrease the aging time, a hydrothermal method was adopted. ${ }^{19,20}$

Briefly, $0.2 \mathrm{~g}$ of PVP (used to improve the dispersivity of particles in the hydrothermal process ${ }^{20,21}$ ) was added to a $25 \mathrm{~mL}$ solution containing $1.7 \mathrm{~g} \mathrm{Fe}\left(\mathrm{NO}_{3}\right)_{3} \cdot 9 \mathrm{H}_{2} \mathrm{O}$. Then, a $9 \mathrm{~mL}$ solution of $\mathrm{NaOH}(5 \mathrm{M})$ was added to the mixture under vigorous stirring. After $3 \mathrm{~h}$, stirring was stopped, and the stable suspension was transferred into a $100 \mathrm{~mL}$ Teflon-lined stainless-steel autoclave that was maintained at $120^{\circ} \mathrm{C}$ for $12 \mathrm{~h}$.

When cooled down to environment temperature, the sediment was washed three times with deionized water and anhydrous ethanol alternately. The product was obtained after drying at $60{ }^{\circ} \mathrm{C}$ for $6 \mathrm{~h}$.

2.2.2. Synthesis of the $\boldsymbol{\beta}$-FeOOH catalyst. $\beta$-FeOOH was prepared by the hydrolysis of a $\mathrm{Fe}(\mathrm{III})$ chloride solution. In the synthesis process, chloride ion occupies the $0.5 \times 0.5 \mathrm{~nm}^{2}$ interstices in the tunnels of the structure and appears to direct this structure and stabilize it. $\beta-\mathrm{FeOOH}$ cannot be prepared at $\mathrm{pH}>5$ because $\mathrm{OH}^{-}$ion is far more competitive than chloride ion for structural sites. ${ }^{18}$

The $\beta$-FeOOH catalyst was synthesized by a direct hydrolysis method. The typical synthesis was as follows: $1.62 \mathrm{~g}$ of $\mathrm{FeCl}_{3}$ $\cdot 6 \mathrm{H}_{2} \mathrm{O}$ was dissolved in $150 \mathrm{~mL}$ of deionized water, and the solution was continuously stirred for $15 \mathrm{~h}$ at $80{ }^{\circ} \mathrm{C}$. Then, a suspension was obtained. After centrifugation, it was washed 3 times with deionized water and dried at $60{ }^{\circ} \mathrm{C}$ for $6 \mathrm{~h}$ to obtain the product.

2.2.3. Synthesis of the $\gamma$-FeOOH catalyst. $\gamma$-FeOOH was conveniently synthesized by oxidizing an $\mathrm{Fe}^{2+}$-containing solution at a $\mathrm{pH}$ close to neutral, and the $\mathrm{pH}$ needed to be maintained during the entire process to ensure that protons could be produced: ${ }^{18}$

$$
4 \mathrm{Fe}^{2+}+\mathrm{O}_{2}+6 \mathrm{H}_{2} \mathrm{O} \rightarrow 4 \gamma-\mathrm{FeOOH}+8 \mathrm{H}^{+}
$$

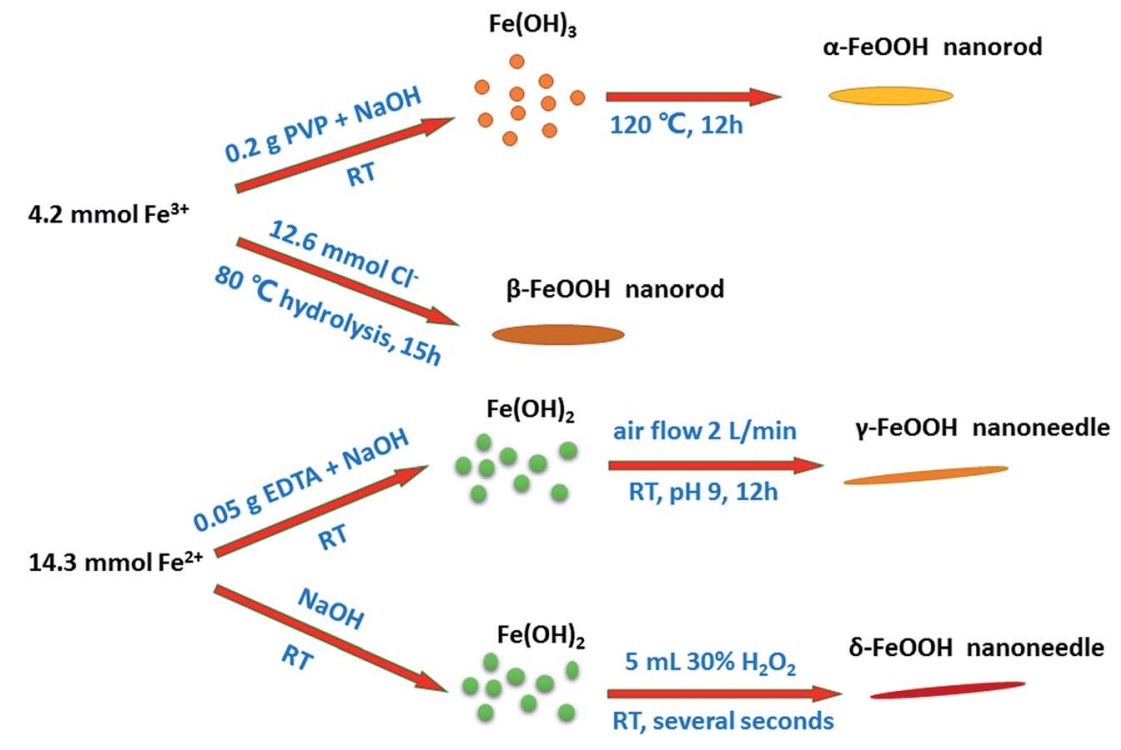

Fig. 1 Proposed schematic of the synthesis of different crystal structures of FeOOH nanorods/needles. 
The $\gamma$-FeOOH catalyst was synthesized by an easy precipitation method. Herein, $0.05 \mathrm{~g}$ of EDTA (used to ensure the purity of $\gamma$-crystals and inhibit the generation of $\left.\alpha-\mathrm{FeOOH}^{22,23}\right)$ was added to a $100 \mathrm{~mL}$ solution containing $3.97 \mathrm{~g}$ of $\mathrm{FeSO}_{4} \cdot 7 \mathrm{H}_{2} \mathrm{O}$. Then, the $\mathrm{pH}$ of the solution was adjusted to $6.5-7.5$ by adding $\mathrm{NaOH}$ dropwise under vigorous stirring. Moreover, the bubbling started with an air rate of $2 \mathrm{~L} \mathrm{~min}^{-1}$ for $12 \mathrm{~h}$. The solid precipitate was obtained by centrifugation and washing 3 times with deionized water. The final product was obtained after drying at $60{ }^{\circ} \mathrm{C}$ for $6 \mathrm{~h}$.

2.2.4. Synthesis of the $\delta$-FeOOH catalyst. $\delta$-FeOOH is a ferrimagnetic mineral that is usually produced by the $\mathrm{H}_{2} \mathrm{O}_{2}$ oxidation of $\mathrm{Fe}(\mathrm{OH})_{2}$ at a high $\mathrm{pH}$. Very rapid oxidation is essential for the formation of $\delta$-FeOOH because if the oxidation rate is lowered, $\gamma$-FeOOH or $\mathrm{Fe}_{3} \mathrm{O}_{4}$ may form. ${ }^{18}$

The $\delta$-FeOOH catalyst was synthesized by a modified precipitation method. Typically, $3.97 \mathrm{~g}$ of $\mathrm{FeSO}_{4} \cdot 7 \mathrm{H}_{2} \mathrm{O}$ was dissolved in $100 \mathrm{~mL}$ of deionized water. Then, a $20 \mathrm{~mL}$ solution of $\mathrm{NaOH}(5 \mathrm{M})$ was immediately added to the metal ion solution under vigorous stirring. After this, $5 \mathrm{~mL}$ of $30 \% \mathrm{H}_{2} \mathrm{O}_{2}$ was injected into it to provide the necessary rapid oxidation for the formation of crystalline structures. ${ }^{24-26}$ After $1 \mathrm{~min}$, the precipitate was centrifuged and washed 3 times with deionized water. The final product was obtained after drying at $60{ }^{\circ} \mathrm{C}$ for $6 \mathrm{~h}$.

\subsection{Characterization of the catalysts}

Transmission electron microscopy (TEM) and high-resolution TEM (HRTEM) were employed to investigate the morphology and microstructure of the catalysts (JEOL, JEM-2100F, Japan, working at $200 \mathrm{kV}$ ). The X-ray powder diffraction (XRD) pattern was employed to determine the crystallinity of the catalysts (Empyrean, Manalytical, the Netherlands) at $40 \mathrm{kV}$ and $30 \mathrm{~mA}$ over the $2 \theta$ range $10-80^{\circ}$. X-ray photoelectron spectroscopy (XPS) experiments were used to identify the valency of elements (Escalab 250Xi, Thermo Fisher Scientific, US). The BrunauerEmmett-Teller (BET) method was used to measure the specific surface area and the pore structure of the catalysts (ASAP 2020, Quantachrome, US, performed at $77 \mathrm{~K}$ ). Moreover, the isoelectric point $\left(\mathrm{pH}_{\mathrm{pzc}}\right)$ was measured by zetasizer (Malvern U.K.). Thermogravimetric analysis (TGA) was carried out using a TGA/ DSC1 STAR thermogravimetric analyzer from 50 to $400{ }^{\circ} \mathrm{C}$ at a heating rate of $3{ }^{\circ} \mathrm{C} \min ^{-1}$ in a $\mathrm{N}_{2}$ flow.

\subsection{Catalytic experiments}

Catalytic experiments were conducted in common $250 \mathrm{~mL}$ conical flasks at $25{ }^{\circ} \mathrm{C}$ with $120 \mathrm{rpm}$. The catalyst suspensions were prepared by dispersing the catalysts in flasks with deionized water under ultrasonication (Xinzhing Co., Ltd, China). Then, some AO7 solution $\left(1.0 \mathrm{~g} \mathrm{~L}^{-1}\right)$ and oxone solution $(0.1 \mathrm{M})$ were added to the mixture. Moreover, the $\mathrm{pH}$ of the reaction mixture was adjusted using $0.1 \mathrm{M} \mathrm{HCl}$ and $0.1 \mathrm{M} \mathrm{NaOH}$. After all the abovementioned steps, the total volume of each suspension was adjusted to $100 \mathrm{~mL}$ with deionized water.

The AO7 concentration was analyzed using a spectrophotometer (T9, Persee, China) at $484 \mathrm{~nm}$ immediately after the suspensions were filtered through $0.22 \mu \mathrm{m}$ hydrophilic polyethersulfone membranes (Huaxia Co. Ltd, China). The concentration of iron ion was analyzed by inductively coupled plasma atomic emission spectroscopy (ICP-MS, Elemental Scientific, US). Moreover, the generated radical products were analyzed via competitive dynamics by bringing in a radical scavenger and detected by an electron spin resonance spectrometer (ESR) (Albutran, AXM-09, US).

\section{Results and discussion}

\subsection{Characterization of $\mathrm{FeOOH}$}

The crystal structures of the four FeOOH catalysts were analyzed by wide-angle XRD patterns, as shown in Fig. 2 . It could be seen that all of them corresponded to the standardized structures of JCPDS, and no other phases were found. For $\alpha$-FeOOH, sharp diffraction peaks appeared at $17.7^{\circ}, 21.1^{\circ}, 26.3^{\circ}, 33.2^{\circ}, 34.6^{\circ}$, $36.6^{\circ}, 39.9^{\circ}, 41.1^{\circ}, 53.2^{\circ}, 59.0^{\circ}$, and $61.2^{\circ}$, which agreed well with those of goethite (JCPDS 29-0713). In addition, the pattern of $\beta-\mathrm{FeOOH}$ showed peaks, which appeared mainly at $11.9^{\circ}$, $16.8^{\circ}, 26.7^{\circ}, 34.0^{\circ}, 35.2^{\circ}, 39.2^{\circ}, 43.1^{\circ}, 46.5^{\circ}, 52.1^{\circ}, 55.9^{\circ}, 61.3^{\circ}$, $64.2^{\circ}$, and $67.9^{\circ}$, that were consistent with those of akaganeite (JCPDS 75-1549). The crystal configuration of $\gamma$-FeOOH was similar to that of lepidocrocite (JCPDS 08-0098), which had sharp diffraction peaks appearing at $14.2^{\circ}, 27.2^{\circ}, 36.5^{\circ}, 46.9^{\circ}$, $53.2^{\circ}$, and $59.0^{\circ}$. In addition, $\delta-\mathrm{FeOOH}$, consistent with feroxyhyte (JCPDS 13-0087), possessed sharp diffraction peaks at $35.2^{\circ}, 40.6^{\circ}, 54.5^{\circ}$, and $63.1^{\circ}$.

The morphologies and microstructures were observed by TEM and HRTEM. As can be seen in Fig. 3(a), $\alpha-\mathrm{FeOOH}$ exhibited the morphology of short irregular nanorods. On the other hand, the morphology of $\beta$-FeOOH was a regular spindleshape with a length of $200 \mathrm{~nm}$, as shown in Fig. 3(b). The morphology of $\gamma$-FeOOH shown in Fig. 3(c) was needle-like particles with most widths between 20 and $30 \mathrm{~nm}$. $\delta$-FeOOH had a completely similar microstructure (Fig. 3(d)) to $\gamma-\mathrm{FeOOH}$, which also exhibited needle-like particles. Furthermore, as observed in the HRTEM image (Fig. 3(e)), the lattice fringe spacings of feroxyhyte-structure of $\delta$-FeOOH were about $0.29 \mathrm{~nm}$ for the (100) plane and $0.23 \mathrm{~nm}$ for the (002) plane.

Fig. 4 displays the $\mathrm{N}_{2}$ physisorption isotherm and pore diameter distribution of various FeOOH solids. Both the BET surface areas and average pore diameters are listed in Table 1. It can be seen that $\delta$-FeOOH has highest BET surface area, whereas $\alpha$-FeOOH displays lowest BET surface area. According to the pore diameter distribution results, macropores are dominant in $\alpha$ - and $\gamma$-FeOOH because of the formation of a loose structure intermediate with the quick-added precipitator. $^{27}$ On the other hand, $\beta-\mathrm{FeOOH}$ is rich in micropores, which are induced by the slow process of hydrolysis. ${ }^{28}$ It is interesting to note the highly centralized distribution of mesoporous structures of $\delta-\mathrm{FeOOH}$. This can be further confirmed by the type IV isotherm of its adsorption-desorption curve. ${ }^{29,30}$ The abundant mesopores may be related to the microbubbles produced by $\mathrm{H}_{2} \mathrm{O}_{2}$ decomposition during the preparation. The $\mathrm{pH}_{\mathrm{pzc}}$ values of the four materials $\left(\alpha-, \beta-, \gamma^{-}\right.$, and $\delta$-FeOOH) were $6.82,7.31,6.38$, and 5.84 , which were roughly consistent with 

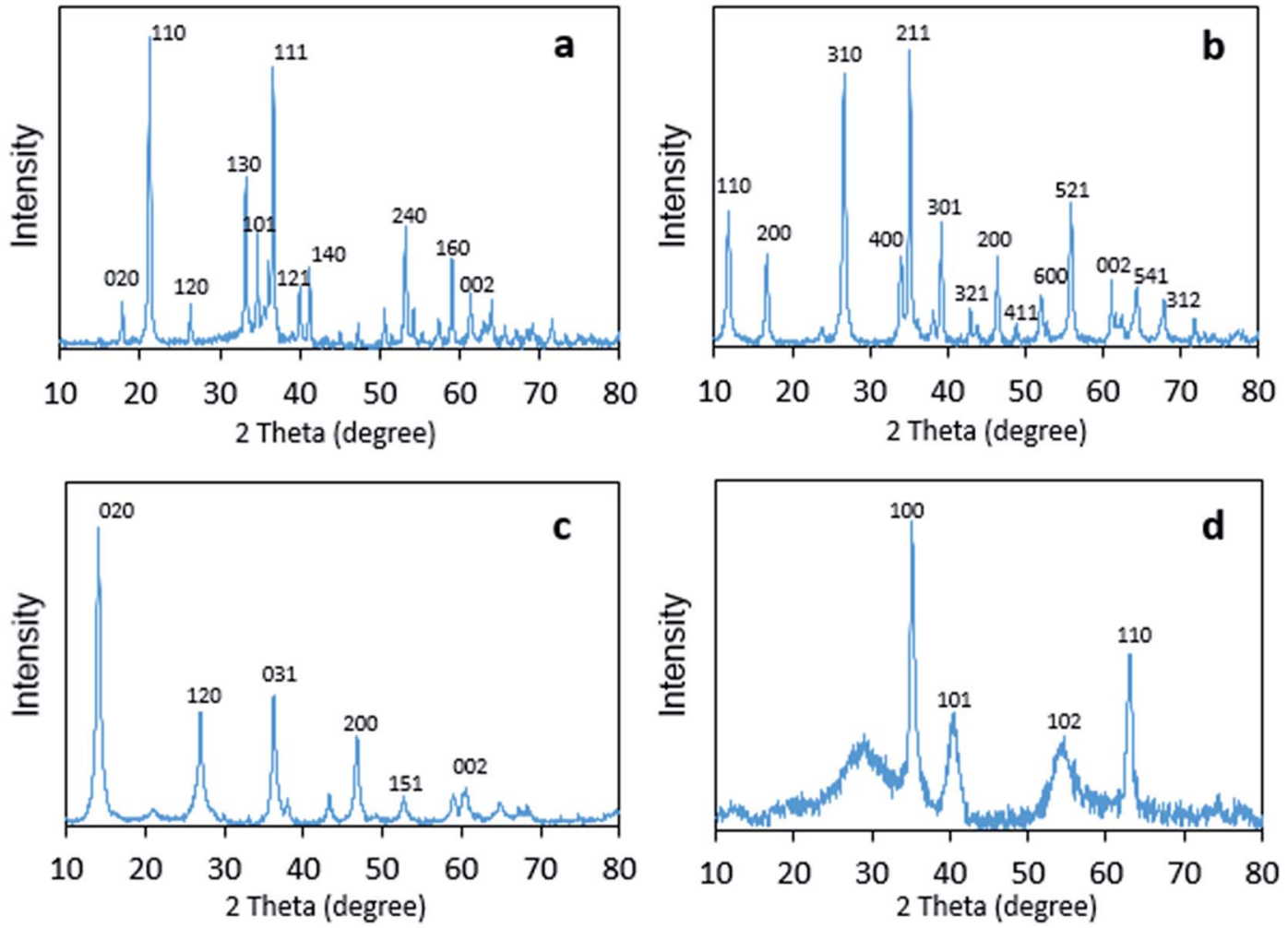

Fig. 2 Powder X-ray diffraction patterns of (a) $\alpha-\mathrm{FeOOH}$, (b) $\beta$-FeOOH, (c) $\gamma-\mathrm{FeOOH}$, and (d) $\delta$-FeOOH.
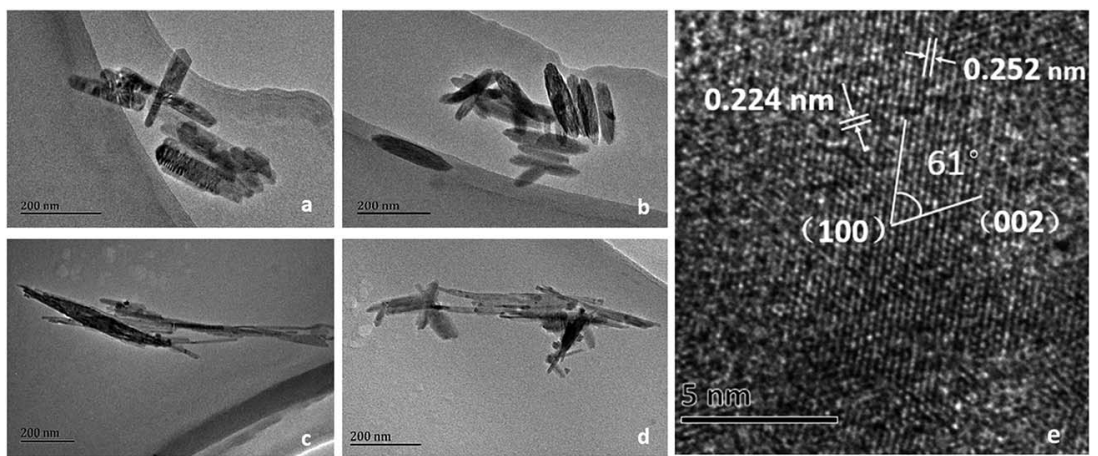

Fig. 3 TEM and HRTEM images of (a) $\alpha-\mathrm{FeOOH}$, (b) $\beta-\mathrm{FeOOH}$, (c) $\gamma-\mathrm{FeOOH}$, and (d) $\delta$-FeOOH; (e) HRTEM image of $\delta$ - $\mathrm{FeOOH}$.

the values reported in literature. ${ }^{31}$ All the results may be associated with different crystal types.

\subsection{Catalytic activity of different FeOOH catalysts}

The adsorption and degradation of $\mathrm{AO} 7$ on various $\mathrm{FeOOH}$ solids are displayed in Fig. 5. It can be seen that all four materials demonstrated adsorption efficiencies for AO7. However, mere adsorption is highly limited to the removal of pollutants. As can be seen in Fig. 5(a), within $120 \mathrm{~min}, \alpha$ $\mathrm{FeOOH}, \beta$-FeOOH, and $\gamma$-FeOOH have similar adsorption efficiencies (27\% for $\alpha-, 24.4 \%$ for $\beta$-, and $23.7 \%$ for $\gamma$-), whereas $\delta$ $\mathrm{FeOOH}$ has the highest adsorption efficiency (39.7\%).

Moreover, similar trends could be observed for degrees of discoloration when different forms of $\mathrm{FeOOH}$ were combined with PMS. It can be seen from Fig. 5(b) that the decolorization efficiency is as high as $91.4 \%$ in the $\delta$-FeOOH/PMS system as compared to that of the other three groups $(42 \%$ for $\alpha-\mathrm{FeOOH} /$ PMS, $24.9 \%$ for $\beta$-FeOOH/PMS, and $29.5 \%$ for $\gamma$-FeOOH/PMS) after $30 \mathrm{~min}$ of the catalytic reaction. In addition, simple addition of PMS to the AO7 solution resulted in almost no discoloration (4.7\%). Thus, it is obvious that $\alpha$-FeOOH and $\delta$ $\mathrm{FeOOH}$ have activation capacities for PMS, whereas $\beta-\mathrm{FeOOH}$ and $\gamma$-FeOOH does not, and the activation capacity of $\delta$-FeOOH is much stronger than that of $\alpha-\mathrm{FeOOH}$.

Ji et al. have found that the higher PMS activation capacity of the prepared porous $\alpha-\mathrm{Fe}_{2} \mathrm{O}_{3}$ as compared to that of the commercial $\alpha-\mathrm{Fe}_{2} \mathrm{O}_{3}$ may be attributed to the larger surface area of the former. ${ }^{32}$ Saputra et al. found that $\alpha-\mathrm{MnO}_{2}$ exhibited 

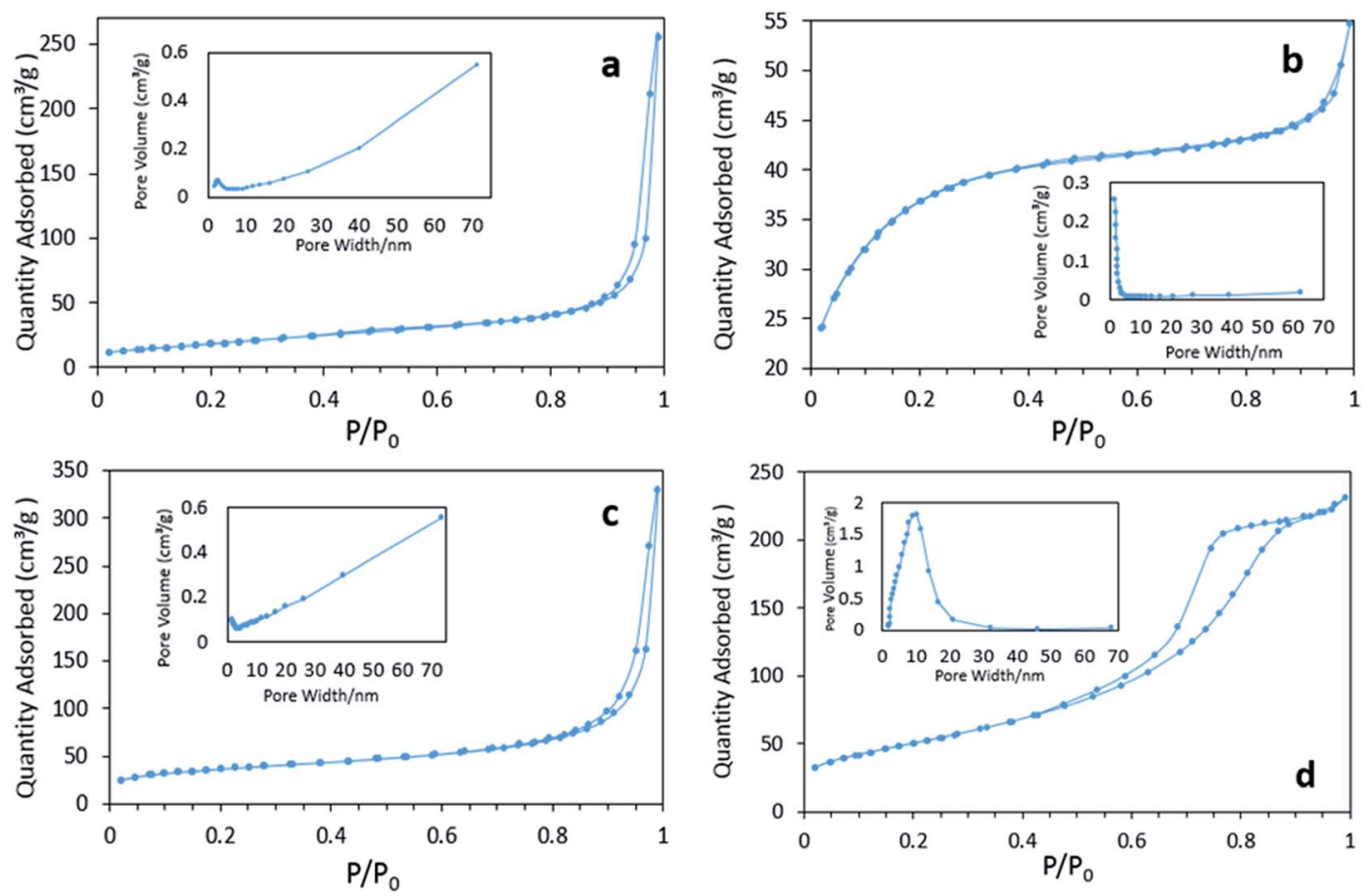

Fig. 4 The $\mathrm{N}_{2}$ absorption/desorption isotherm curves and pore size distributions of catalysts: (a) $\alpha-\mathrm{FeOOH}$, (b) $\beta-\mathrm{FeOOH}$, (c) $\gamma-\mathrm{FeOOH}$, and (d) $\delta-\mathrm{FeOOH}$

Table 1 Physicochemical properties of the four different FeOOH catalysts

\begin{tabular}{lclll}
\hline $\begin{array}{l}\text { The crystal } \\
\text { type }\end{array}$ & $\begin{array}{l}S_{\mathrm{BET}} \\
\left(\mathrm{m}^{2} \mathrm{~g}^{-1}\right)\end{array}$ & $\begin{array}{l}\text { Volume of pores } \\
\left(\mathrm{cm}^{3} \mathrm{~g}^{-1}\right)\end{array}$ & $\begin{array}{l}\text { Average pore } \\
\text { width }(\mathrm{nm})\end{array}$ & $\mathrm{pH}_{\mathrm{pzc}}$ \\
\hline & & & & \\
$\alpha$-FeOOH & 64.1 & 0.50 & 21.73 & 6.82 \\
$\beta-\mathrm{FeOOH}$ & 133.6 & 0.06 & 3.32 & 7.31 \\
$\gamma$-FeOOH & 131.4 & 0.39 & 18.80 & 6.38 \\
$\delta$-FeOOH & 179.7 & 1.24 & 6.46 & 5.84
\end{tabular}

higher adsorption due to its larger surface area, which promoted the reaction between the sulfate radical and phenol. ${ }^{\mathbf{1 6}}$ Wang et al. reported that meso-CuFe $\mathrm{O}_{4}$ with a high surface area displayed a higher catalytic activity than commercial $\mathrm{CuFe}_{2} \mathrm{O}_{4} \cdot{ }^{33}$ Among the four FeOOH solids, $\delta$-FeOOH has more surface area than the other three, which provides more active sites in the adsorption and heterogeneous catalytic reaction.

Moreover, the effect of the crystalline structures of the catalysts cannot be ignored. The atomic configurations of all four crystal structures of $\mathrm{FeOOH}$ polymorphs are given in Fig. S1. $\dagger \alpha-\mathrm{FeOOH}$ has the same structure as diaspore $\left(\alpha\right.$-AlOOH), a typical orthorhombic system. $\mathrm{Fe}^{3+}$ in crystals is hexagonal close packed to make $\left[\mathrm{FeO}_{3}(\mathrm{OH})_{3}\right]$ an octahedral structure with anions around. ${ }^{34} \beta-\mathrm{FeOOH}$ belongs to the tetragonal system with a $(2 \times 2)$ tunnel structure. ${ }^{18} \gamma$ - and $\delta$ $\mathrm{FeOOH}$ are layered crystal structures constituted by octahedral $\left[\mathrm{FeO}_{6}\right]$, belonging to the orthorhombic system and hexagonal
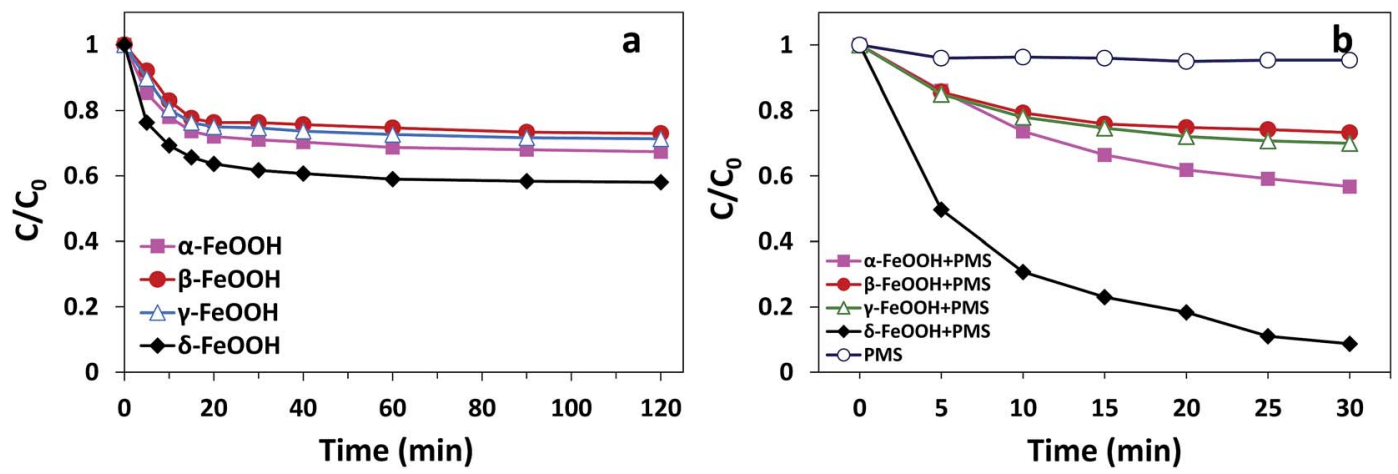

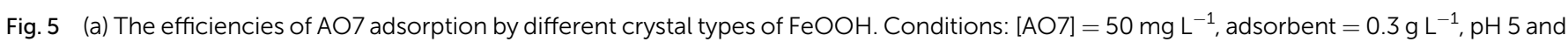
$t=25 \pm 1^{\circ} \mathrm{C}$. (b) The degradation efficiency of $\mathrm{AO} 7 \mathrm{in} \mathrm{FeOOH} / \mathrm{PMS}$ systems. Conditions: $[\mathrm{AO}]=50 \mathrm{mg} \mathrm{L}{ }^{-1}, \mathrm{PMS}: \mathrm{AO}$ ( $\left.\mathrm{mol}\right)=20: 1, \mathrm{catalyst}=$ $0.3 \mathrm{~g} \mathrm{~L}^{-1}, \mathrm{pH} 5$ and $t=25 \pm 1^{\circ} \mathrm{C}$. 
system, respectively. ${ }^{35}$ Because of the abovementioned different structures, the bound water has different locations in the crystal; this leads to hydration of different strengths. Therefore, TGA analysis was performed to demonstrate the location of the structural water in different FeOOH solids. As shown in Fig. 6, $\delta$ FeOOH exhibited highest weight loss of surface adsorbed water from room temperature to $150{ }^{\circ} \mathrm{C}$. Previous studies have reported that water adsorbed on the surface of catalysts can enhance the catalytic rate. ${ }^{36,37}$ Therefore, the more amount of surface water may induce a higher catalytic activity. $\delta$-FeOOH showed the highest amount of adsorbed water loss from TGA, which was coincident with the result of its highest catalytic efficiency. Due to its excellent specific surface area and crystalline structure, $\delta$-FeOOH owns most active sites among the four solids, leading to the best catalytic activity. However, $\alpha$ $\mathrm{FeOOH}$ with a lower surface area presented a higher catalytic efficiency than $\gamma$-FeOOH although their hydrations were similar. This could be attributed to the relatively weak surface FeO-H bonds of $\alpha-\mathrm{FeOOH}$ that seemed to favor the interaction of surface hydroxyl groups with $\mathrm{HSO}_{5}{ }^{-} .^{31}$ The relatively weak surface $\mathrm{FeO}-\mathrm{H}$ bonds of the hydroxylated $\alpha$-FeOOH lead to a high affinity of its electrophilic $\mathrm{H}$; this makes the surface $\mathrm{OH}$ PMS combination easy. Therefore, the surface hydroxyl groups of $\alpha$-FeOOH exhibited higher catalytic activity than $\gamma$-FeOOH in promoting PMS decomposition.

\subsection{Effect of reaction conditions on $\mathrm{AO} 7$ degradation}

In the following experiments, $\delta$-FeOOH was mainly used as a heterogeneous catalyst to investigate the influence of various factors, including catalyst dosage, oxidant dosage, and $\mathrm{pH}$, on the catalytic process.

3.3.1. Effect of catalyst dosage. The effect of catalyst dosage on $\mathrm{AO} 7$ degradation in the $\delta$-FeOOH/PMS system is presented in Fig. 7. As displayed, the AO7 degradation under different catalyst dosages was consistently well-fitted by the pseudo-firstorder kinetic model, whereas the amount of the catalyst had a significant influence on the AO7 degradation process. When

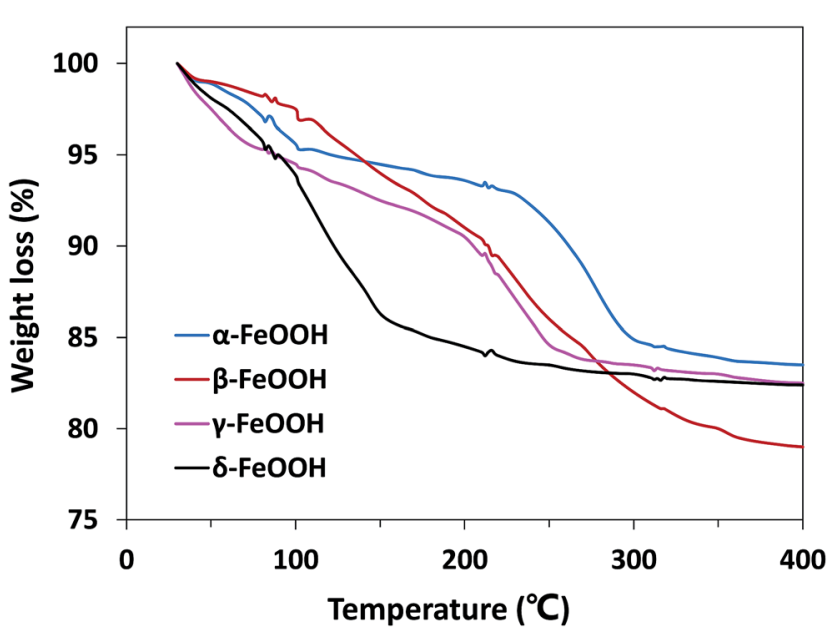

Fig. 6 TGA curves for $\alpha$ - $\mathrm{FeOOH}, \beta-\mathrm{FeOOH}, \gamma-\mathrm{FeOOH}$, and $\delta$ - $\mathrm{FeOOH}$ compounds (heating rate: $3^{\circ} \mathrm{C} \mathrm{min}^{-1}$ ).

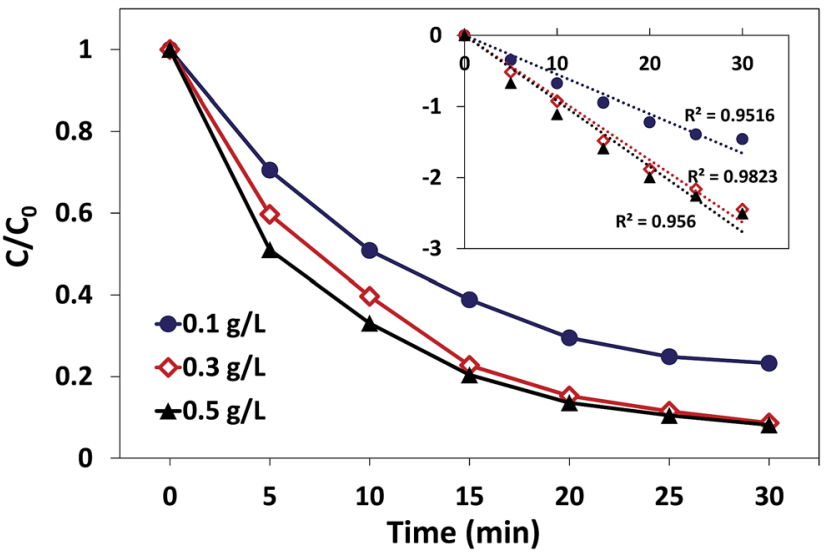

Fig. 7 Effect of catalyst dosage on $\mathrm{AO} 7$ degradation in the $\delta-\mathrm{FeOOH} /$ PMS process. Conditions: $[\mathrm{AO} 7]=50 \mathrm{mg} \mathrm{L}^{-1}, \mathrm{PMS}: \mathrm{AO} 7(\mathrm{~mol})=20: 1$, $\mathrm{pH} 5$ and $t=25 \pm 1{ }^{\circ} \mathrm{C}$.

the dosage of the catalyst increased from $0.1 \mathrm{~g} \mathrm{~L}^{-1}$ to $0.3 \mathrm{~g} \mathrm{~L}^{-1}$, the degradation rate increased from $0.055 \mathrm{~min}^{-1}$ to $0.088 \mathrm{~min}^{-1}$, and the decolorization efficiency was promoted from $76.8 \%$ to $91.4 \%$ in $30 \mathrm{~min}$. The notable improvement might be attributed to more active sites provided by more catalysts such that more radicals could be produced in a short time. ${ }^{38}$ However, the decolorization efficiency only increased to $92.8 \%$, and the degradation rate increased to $0.092 \mathrm{~min}^{-1}$ when the catalyst dosage was increased to $0.5 \mathrm{~g} \mathrm{~L}^{-1}$. This might be related to the insufficient concentration of PMS in the reaction systems with high catalyst dosages.

3.3.2. Effect of the oxidant dosage. Oxidant dosage can be represented by the mole ratio of oxidant (PMS) and substrate (AO7). The influence of the mole ratio of PMS/AO7 on degradation process is illustrated in Fig. 8. When the mole ratio of $\mathrm{PMS} / \mathrm{AO} 7$ was changed from $10: 1$ to $30: 1$, the degradation rate constant rapidly increased from 0.063 to $0.099 \mathrm{~min}^{-1}$. However, when the mole ratio was increased from $30: 1$ to $50: 1$, the rate decreased from 0.099 to $0.093 \mathrm{~min}^{-1}$. This phenomenon is

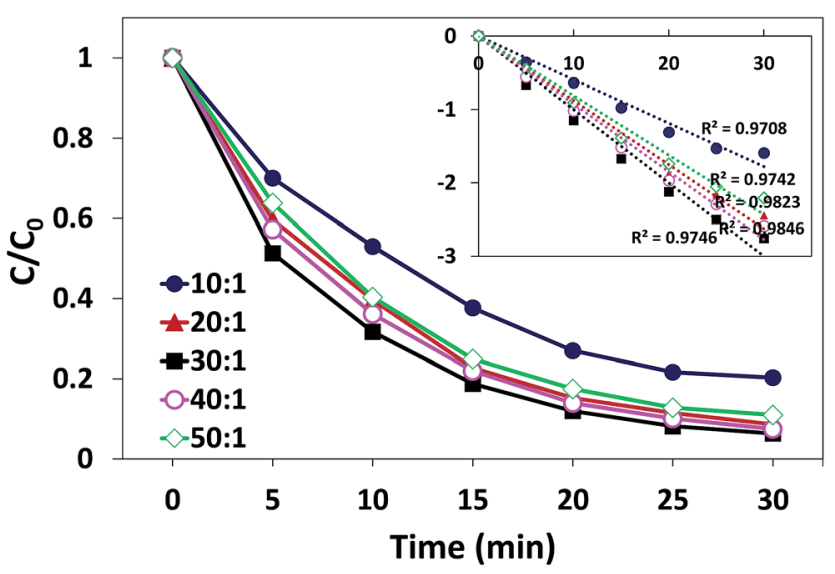

Fig. 8 Effect of oxidant dosage (mole ratio of PMS : AO7) on AO7 degradation in the $\delta$-FeOOH/PMS process. Conditions: [AO7] $=$ $50 \mathrm{mg} \mathrm{L}^{-1}$, catalyst $=0.3 \mathrm{~g} \mathrm{~L}^{-1}, \mathrm{pH} 5$, and $t=25 \pm 1{ }^{\circ} \mathrm{C}$. 
consistent with many other heterogeneous catalytic reactions for the activation of PMS. ${ }^{39}$ The increase in PMS concentration within a certain range is conducive for producing more free radicals to attack pollutants. However, too many unreacted PMS in the solution will quench the produced free radicals as shown in the following reaction: ${ }^{40}$

$$
\begin{gathered}
\mathrm{SO}_{4}{ }^{-\bullet}+\mathrm{HSO}_{5}{ }^{-} \rightarrow \mathrm{SO}_{5}{ }^{-\cdot}+\mathrm{HSO}_{4}{ }^{-} \\
\cdot \mathrm{OH}+\mathrm{HSO}_{5}{ }^{-} \rightarrow \mathrm{SO}_{5}{ }^{-\cdot}+\mathrm{H}_{2} \mathrm{O}
\end{gathered}
$$

Moreover, the limited active sites of the catalyst hinder the increase in the degradation rate. On the other hand, the degradation efficiency of AO7 was $91.7 \%$ for the molar ratio of $20: 1$ and $93.6 \%$ for $30: 1$; thus, the optimal molar ratio was $20: 1$.

3.3.3. Effect of initial $\mathbf{p H}$. The effect of initial $\mathrm{pH}$ on the degradation process has been demonstrated in Fig. 9. Obviously, the effect of initial $\mathrm{pH}$ on catalysis is significant. The most efficient $\mathrm{AO} 7$ degradation occurred at $\mathrm{pH}$ 5. The degradation rate and decolorization efficiency of $\mathrm{AO} 7$ were $0.088 \mathrm{~min}^{-1}$ and $91.7 \%$, respectively. When $\mathrm{pH}$ was reduced to 3 , the degradation rate decreased to $0.054 \mathrm{~min}^{-1}$, and the decolorization efficiency was $79.3 \%$. When the solution alkalinity was increased, the degradation rate started to decrease. The value was $0.080 \mathrm{~min}^{-1}$ at $\mathrm{pH} 7$ (decolorization efficiency was $88.1 \%$ ), whereas it underwent a sharp decrease to $0.028 \mathrm{~min}^{-1}$ at $\mathrm{pH} 9$ (decolorization efficiency was $60 \%$ ). These results may be related to the charge state of catalyst surface and the species of PMS in the aqueous solution. ${ }^{23,41} \mathrm{The}_{\mathrm{pH}} \mathrm{pzc}$ of $\delta$ $\mathrm{FeOOH}$ is 5.84. Most of the surface hydroxyl groups are at a neutral state when $\mathrm{pH}$ is close to $\mathrm{pH}_{\mathrm{pzc}}$. When $\mathrm{pH}$ is far below or above the $\mathrm{pH}_{\mathrm{pzc}}$, the surface will be charged as follows: ${ }^{31}$

$$
\begin{gathered}
\mathrm{Fe}(\mathrm{III})_{\text {surface }}-\mathrm{OH}+\mathrm{H}^{+} \rightarrow \mathrm{Fe}(\mathrm{III})_{\text {surface }}-\mathrm{OH}_{2}{ }^{+} \\
\mathrm{Fe}(\mathrm{III})_{\text {surface }}-\mathrm{OH}+\mathrm{OH}^{-} \rightarrow \mathrm{Fe}(\mathrm{III})_{\text {surface }}-\mathrm{O}^{-}+\mathrm{H}_{2} \mathrm{O}
\end{gathered}
$$

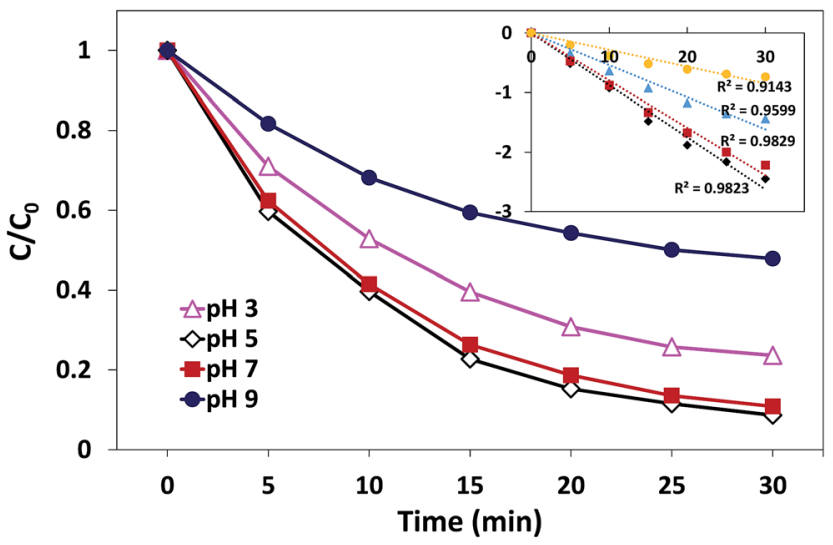

Fig. 9 Effect of initial $\mathrm{pH}$ on $\mathrm{AO} 7$ degradation in the $\delta$-FeOOH/PMS process. Conditions: $[\mathrm{AO} 7]=50 \mathrm{mg} \mathrm{L}-1$, catalyst $=0.3 \mathrm{~g} \mathrm{~L}^{-1}$, PMS : $\mathrm{AO} 7=20: 1$ and $t=25 \pm 1{ }^{\circ} \mathrm{C}$.
Thus, when the $\mathrm{pH}$ is 3 , the catalyst surface is highly protonated, which is unfavorable for the non-polar ends of the accessing organic matter. When $\mathrm{pH}$ was 5 and 7 , both acid centers and alkaline centers existed on the surface of catalysts, which induced the organic matter to easily access the interface. ${ }^{42}$ On the other hand, since the catalyst surface is heavily negatively charged at $\mathrm{pH} 9, \mathrm{HSO}_{5}{ }^{-}$and organic matter hardly interact with the catalysts. Moreover, at $\mathrm{pH} 9, \mathrm{HSO}_{5}{ }^{-}$will further transform into $\mathrm{SO}_{5}{ }^{2-}$; thus, the electrostatic repulsion between the anion and catalysts becomes stronger. ${ }^{23}$ In addition, when solution $\mathrm{pH}$ exceeds 9 , ${ }^{\circ} \mathrm{OH}$ would scavenge $\mathrm{SO}_{4}{ }^{-\cdot}$ and become the dominant active species, ${ }^{31}$ which possesses reduced oxidative capacity. These findings can explain the sharp decrease in the decolorization efficiency at $\mathrm{pH} 9$.

\subsection{Reusability and stability}

Reusability is an important factor that evaluates the performance of the catalyst in practical applications. ${ }^{\mathbf{4 3 4} 4}$ Therefore, successive experiments were conducted to explore the reusability of $\delta$-FeOOH under the same conditions. After each trial, the used catalysts were obtained followed by washing with ethanol and deionized water, separation by centrifugation, and then drying at $60{ }^{\circ} \mathrm{C}$. The catalysts were repeatedly used six times. Table 2 shows the decolorization efficiency of AO7 and the leached concentration of $\mathrm{Fe}^{3+}$ in solution at each catalyst cycle. After recycling for six times, the $\delta$-FeOOH/PMS system could still maintain a high catalytic efficiency. The decolorization efficiency of $\mathrm{AO} 7$ only decreased from $91.7 \%$ to $84.2 \%$. Furthermore, the leached concentration of $\mathrm{Fe}^{3+}$ in the solution after each reaction cycle was determined using ICP-MS. As can be seen from Table 2, the leaching of metal ions was always under $5 \mu \mathrm{g} \mathrm{L} \mathrm{L}^{-1}$. Both these results revealed the high stability of the catalysts, and the degradation reaction occurred at the interface of $\delta$-FeOOH. ${ }^{45}$ In addition, the same successive experiments were carried out on the other three types of crystals, and the decolorization efficiency and the leached concentration of $\mathrm{Fe}^{3+}$ in each experiment are shown in the Tables S1 and $\mathrm{S} 2, \uparrow$ respectively. Besides, the $\mathrm{AO} 7$ degradation in other similar systems has been listed as a comparison (Table 3).

The stability of the crystal structure of catalysts was determined via XRD analysis. As can be seen from Fig. 10, there are no obvious changes in the diffraction peaks of $\delta$-FeOOH after six cycles as compared to those of freshly prepared $\delta$-FeOOH. This result revealed the well stability of the crystal structures of $\delta$ -

Table 2 Decolorization efficiencies and leached metal ion amounts of $\delta$-FeOOH during six consecutive cycles

\begin{tabular}{lll}
\hline Times reused & $\begin{array}{l}\text { Decolorization } \\
\text { efficiency }(\%)\end{array}$ & $\begin{array}{l}\text { Leached iron concentration } \\
\left(\mu \mathrm{g} \mathrm{L}^{-1}\right)\end{array}$ \\
\hline 1 & 91.7 & 4.48 \\
2 & 91.2 & 4.02 \\
3 & 88.1 & 3.22 \\
4 & 87.2 & 2.85 \\
5 & 86.3 & 2.33 \\
6 & 84.2 & 2.01
\end{tabular}


Table 3 The AO7 degradation activity of $\delta$ - $\mathrm{FeOOH} / \mathrm{PMS}$ as compared to that of similar systems

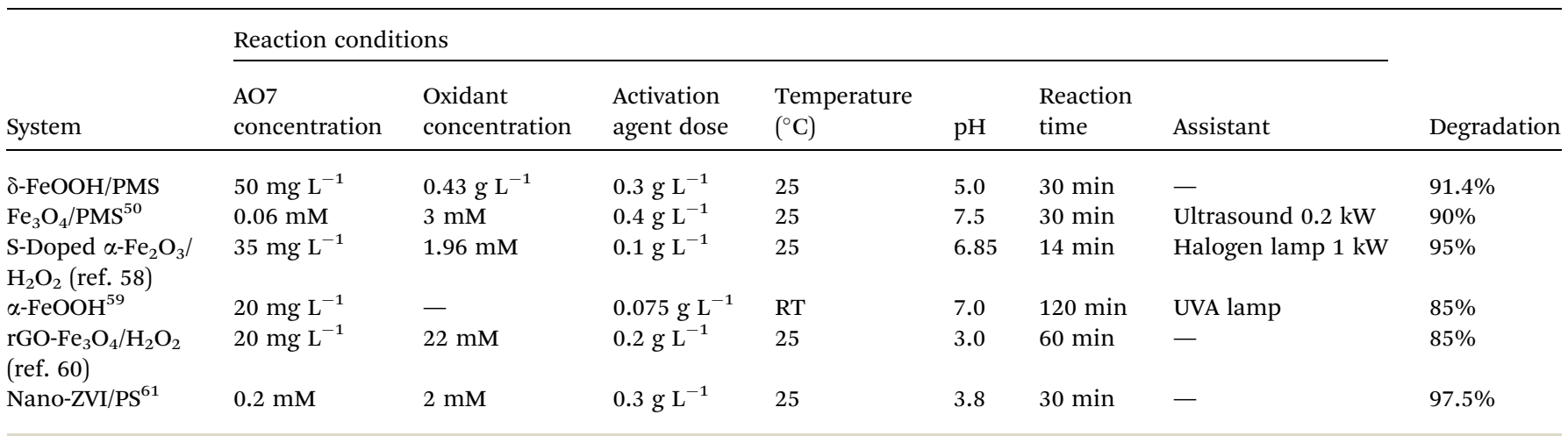

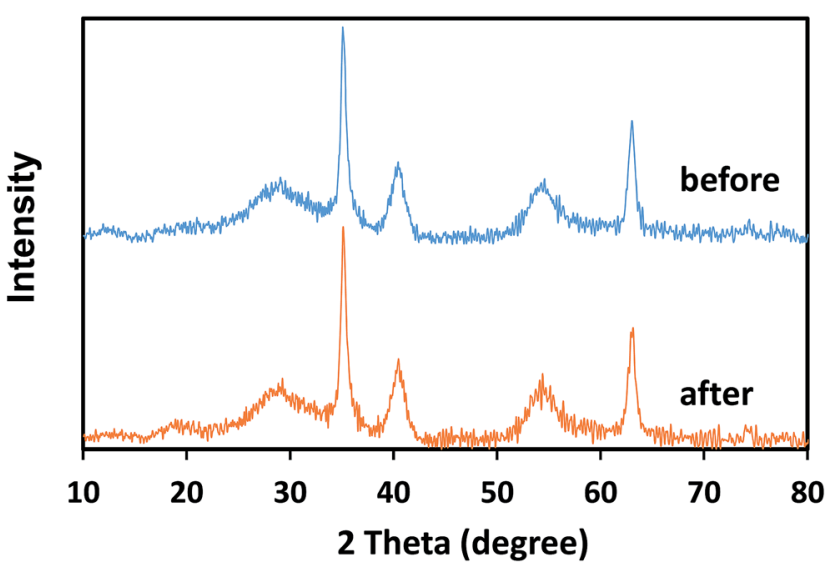

Fig. 10 XRD patterns of synthesized $\delta$-FeOOH before and after its use for 6 times in the PMS/ $\delta-\mathrm{FeOOH} / \mathrm{AO} 7$ system.

FeOOH in the PMS catalytic system. Moreover, the XRD patterns of other three crystal FeOOH are shown in Fig. S2, $†$ and all the crystal structures do not change after the reaction. However, due to the relatively low catalytic efficiency, further studies on them were not carried out.

The elemental changes on the surface of catalysts before and after the reaction cycle could be confirmed via XPS analysis. As can be seen from Fig. 11, the Fe $2 \mathrm{p}_{3 / 2}$ peak was present at $711.0 \mathrm{eV}$ for the fresh catalyst, whereas it was at $711.2 \mathrm{eV}$ for the catalyst after six cycles. The appearance of $0.88 \% \mathrm{Fe}(\mathrm{II})$ in the catalysts after six cycles indicated the occurrence of the reduction process during the reaction. The results indicated that $\delta$ FeOOH was suitable to be used as a PMS activator.

\subsection{Reactive species}

According to previous reports, PMS can produce multiple radicals such as $\mathrm{SO}_{4}{ }^{-\cdot},{ }^{\circ} \mathrm{OH}$, and $\mathrm{SO}_{5}{ }^{-\cdot}{ }^{46}$ Among them, $\mathrm{SO}_{5}{ }^{-\cdot}$ cannot decolorize $\mathrm{AO} 7$ owing to its low oxidative potential. ${ }^{47} \mathrm{To}$ explore which radical $\left(\mathrm{SO}_{4}^{-\cdot}\right.$ or $\left.{ }^{\circ} \mathrm{OH}\right)$ played the major role in the degradation process of $\mathrm{AO} 7$, both ethanol and tert-butanol (TBA) were added to the solution as radical quenching agents. Ethanol can react at a high rate with both $\mathrm{SO}_{4}{ }^{-}$and ${ }^{\circ} \mathrm{OH}\left(k_{\mathrm{SO}_{4}}{ }^{-}\right.$. $\left.=8.6 \times 10^{9} \mathrm{M}^{-1} \mathrm{~s}^{-1} ; k_{\mathrm{OH}}=6.4 \times 10^{9} \mathrm{M}^{-1} \mathrm{~s}^{-1}\right)$. However, TBA

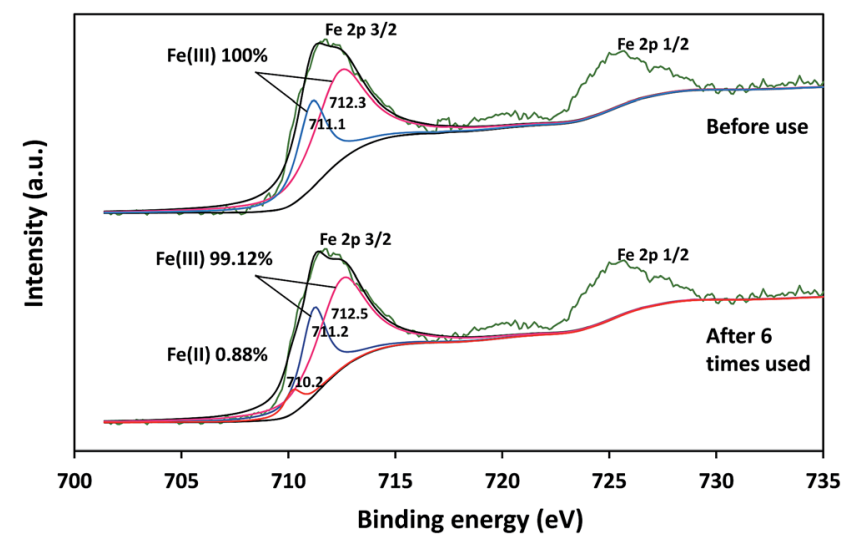

Fig. 11 Fe 2p XPS spectrum of synthesized $\delta$-FeOOH before and after its use for 6 times in the PMS/ $\delta-\mathrm{FeOOH} / \mathrm{AO} 7$ system.

can only react rapidly with ${ }^{\cdot} \mathrm{OH}\left(k_{\cdot \mathrm{OH}}=3.8-7.6 \times 10^{8} \mathrm{M}^{-1} \mathrm{~s}^{-1}\right.$; $\left.k_{\mathrm{SO}_{4}{ }^{-}}=4-9.1 \times 10^{5} \mathrm{M}^{-1} \mathrm{~s}^{-1}\right) .^{48}$ The effect of different quenchers on the degradation of $\mathrm{AO} 7$ in the $\delta$ - $\mathrm{FeOOH} / \mathrm{PMS}$ process is shown in Fig. 12. As presented, the decolorization efficiency was $91.7 \%$ in $30 \mathrm{~min}$ without any quenchers. When $0.5 \mathrm{~mL}$ ethanol was added, the decolorization efficiency decreased to $74.1 \%$. When the amount of ethanol was increased to $5 \mathrm{~mL}$, the decolorization efficiency sharply decreased to $35.9 \%$. When TBA was used as a radical quencher, the decolorization efficiencies under the same conditions were $83.6 \%$ and $62.3 \%$. The results show that the degradation of $\mathrm{AO} 7$ is a radical reaction, and both $\mathrm{SO}_{4}{ }^{-\cdot}$ and ${ }^{\circ} \mathrm{OH}$ are generated in $\delta$-FeOOH/PMS to attack AO7.

To further strongly prove that both $\mathrm{SO}_{4}{ }^{-}$and ${ }^{\circ} \mathrm{OH}$ were generated in the $\delta$-FeOOH/PMS system, ESR tests were conducted to detect $\mathrm{SO}_{4}{ }^{-\cdot}$ and ${ }^{\circ} \mathrm{OH}$ during the catalytic process. DMPO was used as the spin-trapping agent, which formed complexes with $\mathrm{SO}_{4}{ }^{-\cdot}$ and ${ }^{\circ} \mathrm{OH}$. Then, $\mathrm{SO}_{4}{ }^{-\cdot}$ and ${ }^{\circ} \mathrm{OH}$ could be detected by measuring the signals of $\mathrm{DMPO}^{-\mathrm{SO}_{4}}$ adducts and DMPO-OH adducts, respectively. As shown in Fig. 13, the special hyperfine coupling constants $(a(\mathrm{~N}) 1.49 \mathrm{mT}, a(\mathrm{H}) 1.49$ $\mathrm{mT}$, obtained by simulation) are completely consistent with those of DMPO-OH. ${ }^{49}$ Moreover, the special hyperfine coupling constants of $\mathrm{DMPO}^{-\mathrm{SO}_{4}}(a(\mathrm{~N}) 1.38 \mathrm{mT}, a(\mathrm{H}) 1.02 \mathrm{mT}, a(\mathrm{H}) 0.14$ $\mathrm{mT}, a(\mathrm{H}) 0.08 \mathrm{mT}$ ) were obtained by simulation from the 

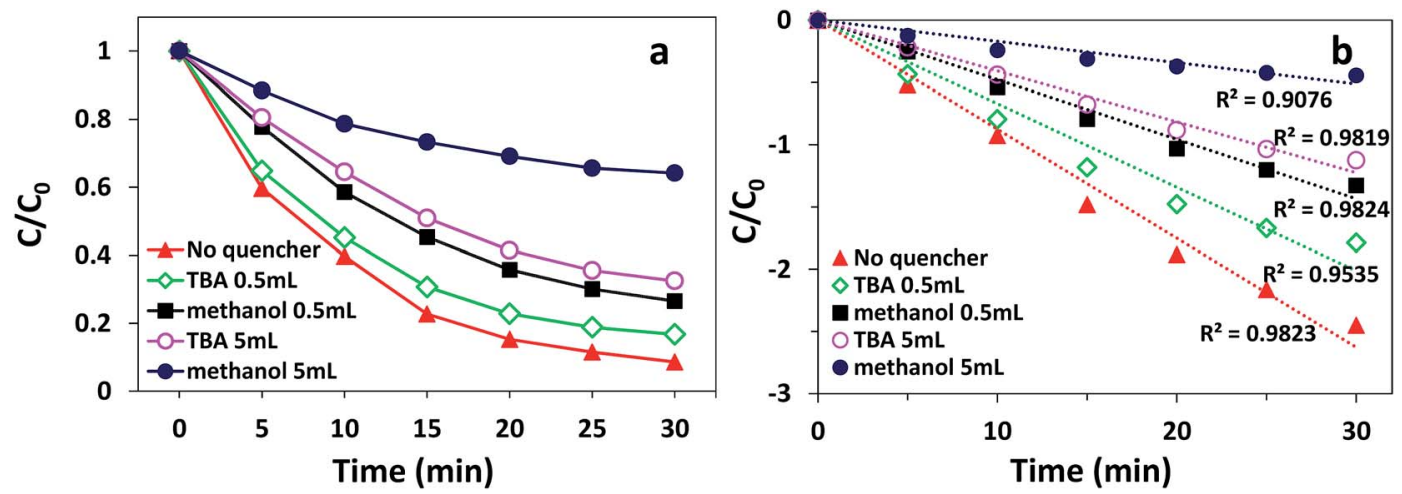

Fig. 12 Radical quenching test on $\mathrm{AO} 7$ degradation in the $\delta$-FeOOH/PMS process: (a) decolorization efficiency and (b) degradation rate fitted by the pseudo-first-order kinetic model. Conditions: [AO7] $=50 \mathrm{mg} \mathrm{L}^{-1}$, catalyst $=0.3 \mathrm{~g} \mathrm{~L}^{-1}$, PMS : AO7 $=20: 1$ and $t=25 \pm 1{ }^{\circ} \mathrm{C}$.

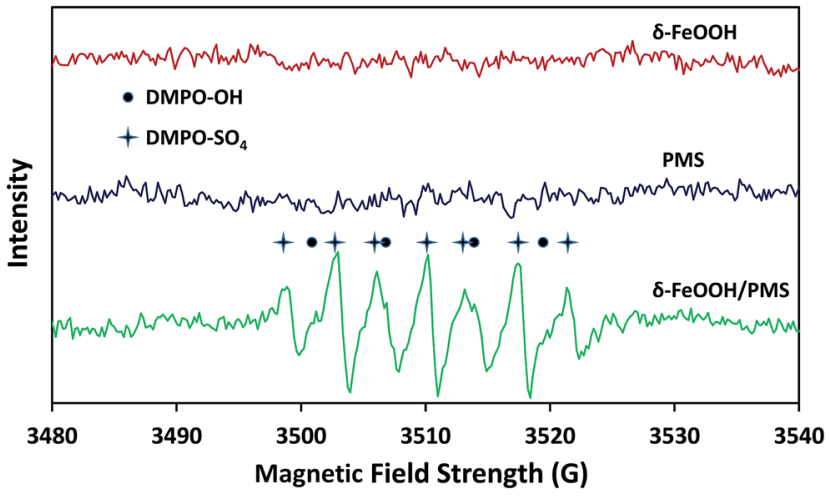

Fig. 13 ESR spectra of the $\delta$-FeOOH particles in deionized water, the PMS solution, and the $\delta$-FeOOH particles in a PMS solution. The black dots represent $\mathrm{DMPO}-\mathrm{OH}$ and the four-pointed stars represent $\mathrm{DMPO}-\mathrm{SO}_{4}$. Conditions: $\delta$ - $\mathrm{FeOOH}=0.3 \mathrm{~g} \mathrm{~L}^{-1}, \mathrm{PMS}=5 \mathrm{mmol} \mathrm{L}$, $[\mathrm{DMPO}]_{0}=10 \mathrm{mmol} \mathrm{L}^{-1}, \mathrm{pH} 5$ and $t=25 \pm 1{ }^{\circ} \mathrm{C}$. The settings for spectrometer: center field, $3510 \mathrm{G}$; sweep width, $120 \mathrm{G}$; frequency, $9.25 \mathrm{GHz}$; modulation frequency, $100 \mathrm{kHz}$; power, $20 \mathrm{~mW}$.

spectra. ${ }^{50}$ All the results further confirmed that both $\mathrm{SO}_{4}{ }^{--}$and ${ }^{\circ} \mathrm{OH}$ were generated in the $\delta$-FeOOH/PMS system.

\subsection{Possible activation mechanism}

It has been reported that the hydroxyl groups on the surface of the metal oxide play an important role in the heterogeneous oxidation reaction. ${ }^{51}$ PMS can combine with the metal oxide through the surface hydroxyl groups and then undergo a redox reaction with the surface metal of oxide to produce the sulfate radical. Moreover, the oxidation state on the surface metal will consistently change with the surface hydroxyl groups. ${ }^{52-54}$ Thus, the in situ spectroscopic analysis could detect the intermediates related to PMS decomposition on the surface of metal oxide.

The in situ characterization of $\delta$-FeOOH surface during catalytic decomposition of PMS was conducted via ATR-FTIR. As shown in Fig. 12, in the PMS solution alone, PMS had two IR bands at $1103 \mathrm{~cm}^{-1}$ and $1249 \mathrm{~cm}^{-1},{ }^{55}$ which originated from S-O of either $\mathrm{HSO}_{5}{ }^{-}$or $\mathrm{SO}_{4}{ }^{2-}$. However, the intensity of $1249 \mathrm{~cm}^{-1}$ had a significant decline when PMS was mixed with $\delta$-FeOOH. Thus, the band at $1249 \mathrm{~cm}^{-1}$ is related to $\mathrm{HSO}_{5}{ }^{-}$. The intensity decline implied the decomposition of PMS on the oxide surface. Moreover, a red-shift by $19 \mathrm{~cm}^{-1}$ of S-O crest at $1249 \mathrm{~cm}^{-1}$ occurred with the addition of $\delta$-FeOOH as compared to the case of the pure PMS solution. This demonstrates that ${ }^{-} \mathrm{OH}$ in $\mathrm{HSO}_{5}{ }^{-}$attracts more electron density from the near $\mathrm{S}-\mathrm{O}$ bond making it weaker; ${ }^{53}$ this may indicate that the surface metal captures electron from $-\mathrm{OH}$, and an increase in the electron attraction from neighboring $\mathrm{S}-\mathrm{O}$ leads to the generation of a sulfate radical.

According to Zhang et al., the stretching vibration of surface hydroxyl is around $3100 \mathrm{~cm}^{-1} .^{56}$ In Fig. 14, there is an intense peak at $3113 \mathrm{~cm}^{-1}$, which indicates the presence of surface $-\mathrm{OH}$ groups on $\delta$-FeOOH. In the presence of $\mathrm{HSO}_{5}{ }^{-}$, this band was red-shifted by $6 \mathrm{~cm}^{-1}$. It is a symbol for the replacement or complexation of the surface $-\mathrm{OH}$ groups by $\mathrm{HSO}_{5}{ }^{-.53}$ this reveals the formation of a complex between $\mathrm{HSO}_{5}{ }^{-}$and metal oxide, and $\mathrm{HSO}_{5}{ }^{-}$loses an electron to the surface $\mathrm{Fe}(\mathrm{III})$ to generate $\mathrm{SO}_{5}{ }^{-\bullet}$.

Based on the analysis of the obtained results, the possible activation mechanism of PMS by $\delta$-FeOOH was proposed. PMS

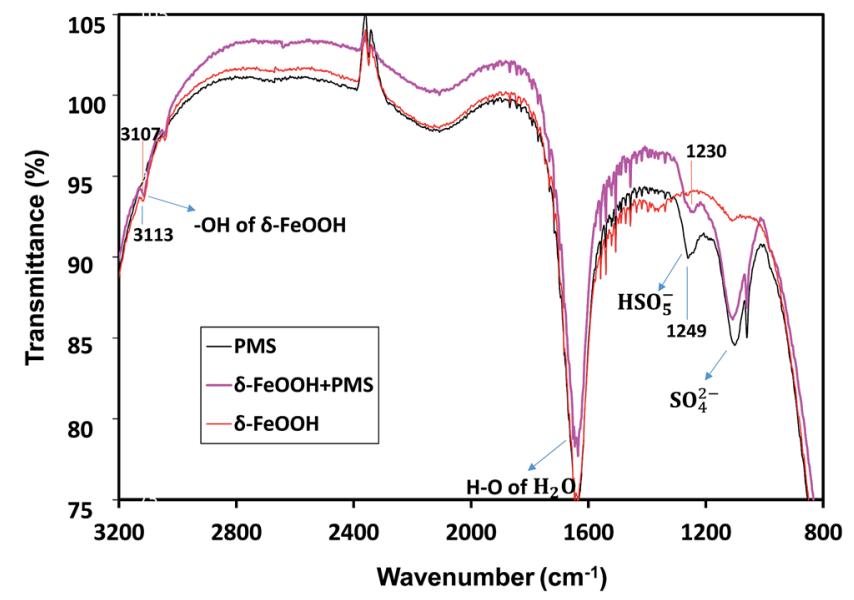

Fig. 14 ATR-FTIR spectra of PMS solution, the $\delta$ - $\mathrm{FeOOH}$ suspension, and the $\delta$-FeOOH particles in the PMS solution. Conditions: $\mathrm{pH} 5$ and $t$ $=25 \pm 1^{\circ} \mathrm{C}$. (The inverse peaks are likely to be owned by the attrite $\mathrm{Ge}$ crystal of ATR attachment.) 


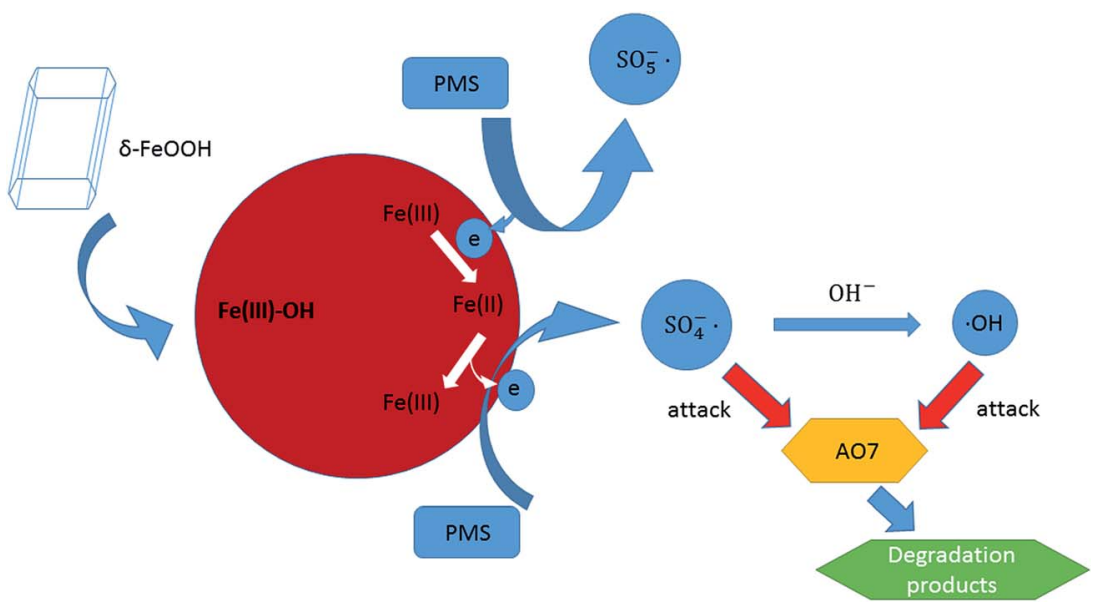

Fig. 15 Speculated activation mechanism in the $\delta$-FeOOH/PMS process.

initially conjuncts with surface $-\mathrm{OH}$ of $\mathrm{FeOOH}(5)$. Then, $\mathrm{SO}_{5}{ }^{-}$. is generated, whereas $\equiv \mathrm{Fe}$ (III) is reduced to $\equiv \mathrm{Fe}($ III), and the generated $\equiv \mathrm{Fe}(\mathrm{II})$ can form a complex with $\mathrm{HSO}_{5}{ }^{-}$(6). Next, $\equiv \mathrm{Fe}(\mathrm{II})$ can be oxidized to $\equiv \mathrm{Fe}$ (III); this releases $\mathrm{SO}_{4}{ }^{-\cdot}$ into the solution (7). ${ }^{57}$ Finally, $\mathrm{SO}_{4}{ }^{-\cdot}$ can react with $\mathrm{OH}^{-}$to produce ${ }^{\circ} \mathrm{OH}$ (8) or directly attack $\mathrm{AO} 7$ (9), both of which are responsible for AO7 degradation (eqn (5)). ${ }^{53}$

$$
\begin{gathered}
\equiv \mathrm{Fe}(\mathrm{III})-\mathrm{OH}+\mathrm{HSO}_{5}{ }^{-} \rightarrow \equiv \mathrm{Fe}(\mathrm{III})-(\mathrm{OH}) \mathrm{SO}_{4}+\mathrm{OH}^{-} \\
\equiv \mathrm{Fe}(\mathrm{III})-(\mathrm{OH}) \mathrm{SO}_{4}+\mathrm{HSO}_{5}^{-} \rightarrow \\
\equiv \mathrm{Fe}(\mathrm{II})-\mathrm{OOSO}_{3}^{-}+\mathrm{SO}_{5}{ }^{-\cdot}+\mathrm{H}^{+} \\
\equiv \mathrm{Fe}(\mathrm{II})-\mathrm{OOSO}_{3}^{-}+\mathrm{H}_{2} \mathrm{O} \rightarrow \equiv \mathrm{Fe}(\mathrm{III})-\mathrm{OH}+\mathrm{SO}_{4}^{-}+\mathrm{OH}^{-} \\
\mathrm{SO}_{4}^{-\cdot}+\mathrm{OH}^{-} \rightarrow \cdot \mathrm{OH}+\mathrm{SO}_{4}{ }^{2-} \\
\mathrm{AO} 7+\mathrm{SO}_{4}^{-\cdot} / \cdot \mathrm{OH} \rightarrow \text { intermediate } \rightarrow \mathrm{CO}_{2}+\mathrm{H}_{2} \mathrm{O}
\end{gathered}
$$

The produced radicals, including $\mathrm{SO}_{4}{ }^{-\cdot}$ and ${ }^{\circ} \mathrm{OH}$, can then attack the chromophore of AO7. All the processes are radical reactions. The proposed activation mechanism of the $\delta-\mathrm{FeOOH} /$ PMS process can be described as shown in Fig. 15.

\section{Conclusion}

In this study, $\mathrm{FeOOH}$ with four different crystalline phases $(\alpha, \beta$, $\gamma$, and $\delta$ ) was synthesized and characterized by XRD, $\mathrm{N}_{2}$ adsorption/desorption, TEM, HRTEM, and other simple methods. Then, they were used as PMS activators for the degradation of AO7. According to the tests, $\delta$-FeOOH was confirmed as a potential catalyst due to its much higher efficiency for PMS activation than others. The catalyst showed stability in element valences and catalytic activity during successive repeated reactions. The degradation reaction was a radical reaction, and both $\mathrm{SO}_{4}{ }^{-}$and ${ }^{\circ} \mathrm{OH}$ were suggested as radical species in the $\mathrm{PMS} / \delta$ - $\mathrm{FeOOH}$ system. The catalytic mechanism was proposed with the aid of the in situ ATR-FTIR analysis and XPS spectra. These results reveal that $\delta$ - $\mathrm{FeOOH}$ is an effective, environmentally friendly, and low cost catalyst for the efficient generation of sulfate radicals and hydroxyl radicals from PMS to degrade organic pollutants. They own a great potential in the advanced oxidative treatment of industrial wastewater and other contaminated water.

\section{Conflicts of interest}

There are no conflicts to declare.

\section{Acknowledgements}

We are thankful for the financial support received from the National Natural Science Foundation of China (Grant No. 51508564).

\section{References}

1 R. C. Costa, M. F. Lelis, L. C. Oliveira, J. D. Fabris, J. D. Ardisson, R. R. Rios, C. N. Silva and R. M. Lago, J. Hazard. Mater., 2006, 129, 171-178.

2 J. Chun, H. Lee, S. H. Lee, S. W. Hong, J. Lee, C. Lee and J. Lee, Chemosphere, 2012, 89, 1230-1237.

3 L. C. A. Oliveira, R. M. Lago, R. V. R. A. Rios, R. Augusti, P. P. Sousa, W. N. Mussel and J. D. Fabris, Stud. Surf. Sci. Catal., 2000, 130, 2165-2170.

4 G. B. O. D. L. Plata, O. M. Alfano and A. E. Cassano, Chem. Eng. J., 2008, 137, 396-410.

5 A. C. D. Silva, M. R. Almeida, M. Rodriguez, A. R. T. Machado, L. C. A. D. Oliveira and M. C. Pereira, J. Photochem. Photobiol., A, 2016, 332, 54-59.

6 Y. Wang, J. Fang, J. C. Crittenden and C. Shen, J. Hazard. Mater., 2017, 329, 321-329.

7 Z. Xia, B. Bo, G. L. Puma, H. Wang and Y. Suo, Chem. Eng. J., 2016, 284, 698-707.

8 M. Sheydaei and A. Khataee, Ultrason. Sonochem., 2015, 27, 616-622.

9 H. Tamura, A. Tanaka, K. Y. Mita and R. Furuichi, J. Colloid Interface Sci., 1999, 209, 225. 
10 A. Babuponnusami and K. Muthukumar, J. Environ. Chem. Eng., 2014, 2, 557-572.

11 L. W. Matzek and K. E. Carter, Chemosphere, 2016, 151, 178.

12 K. Y. A. Lin, J. T. Lin and A. P. Jochems, J. Chem. Technol. Biotechnol., 2017, 92, 163-172.

13 Y. Zhang, H. P. Tran, X. Du, I. Hussain, S. Huang, S. Zhou and W. Wen, Chem. Eng. J., 2017, 308, 1112-1119.

14 Y. Lei, C. S. Chen, Y. J. Tu, Y. H. Huang and H. Zhang, Environ. Sci. Technol., 2015, 49, 6838-6845.

15 Y. Leng, W. Guo, X. Shi, Y. Li, A. Wang, F. Hao and L. Xing, Chem. Eng. J., 2014, 240, 338-343.

16 E. Saputra, S. Muhammad, H. Sun, A. Patel, P. Shukla, Z. H. Zhu and S. Wang, Catal. Commun., 2012, 26, 144-148.

17 F. Ghanbari, M. Moradi and M. Manshouri, J. Environ. Chem. Eng., 2014, 2, 1846-1851.

18 U. Schwertmann and R. M. Cornell, Mineral. Mag., 2000, 61, 740-741.

19 F. Geng, Z. Zhao, J. Geng, H. Cong and H. M. Cheng, Mater. Lett., 2007, 61, 4794-4796.

20 Y. Zhai, X. Ma, H. Mao, W. Shao, L. Xu, Y. He and Y. Qian, Adv. Electron. Mater., 2015, 1, 1400057.

21 Y. H. Guo and Y. Zhang, Mater. Chem. Phys., 1997, 47, 211216.

22 T. F. Barton, T. Price and J. G. Dillard, J. Colloid Interface Sci., 1991, 141, 553-558.

23 T. F. Barton, T. Price and J. G. Dillard, J. Colloid Interface Sci., 1990, 138, 122-127.

24 S. Okamoto, J. Am. Ceram. Soc., 1968, 51, 594-598.

25 C. Rémazeilles and P. Refait, Corros. Sci., 2008, 50, 856-864.

26 P. Refait, O. Benali, M. Abdelmoula and J. M. R. Génin, Corros. Sci., 2003, 45, 2435-2449.

27 P. L. D. Santos, I. R. Guimarães, A. M. Mesquita and M. C. Guerreiro, J. Mol. Catal. A: Chem., 2016, 424, 194-202. 28 S. Li and C. L. Gan, Chem. Phys. Lett., 2014, 616-617, 40-43.

29 T. Jurkin, G. Štefanić, G. Dražić and M. Gotić, Mater. Lett., 2016, 173, 55-59.

30 J. Deng, S. F. Feng, X. Ma, H. Wang, Y. Ni, Y. Lu, T. Zhang and J. Li, Sep. Purif. Technol., 2016, 167, 181-189.

31 T. Zhang, C. Li, J. Ma, H. Tian and Z. Qiang, Appl. Catal., B, 2008, 82, 131-137.

32 F. Ji, C. Li, X. Wei and J. Yu, Chem. Eng. J., 2013, 231, 434440.

33 Y. Liu, X. Liu, Y. Zhao and D. D. Dionysiou, Appl. Catal., B, 2017, 213, 74-86.

34 J. Ma, Q. Yang, Y. Wen and W. Liu, Appl. Catal., B, 2017, 201, 232-240.

35 C. Benoit, C. Bourbon, P. Berthet and S. Franger, J. Phys. Chem. Solids, 2006, 67, 1265-1269.
36 Q. Wang, A. Puntambekar and V. Chakrapani, J. Phys. Chem. C, 2017, 121, 13151-13163.

37 T. Yan, J. Gong, D. W. Flaherty and C. B. Mullins, J. Phys. Chem. C, 2011, 115, 2057-2065.

38 X. Qian, M. Ren, Y. Zhu, D. Yue, Y. Han, J. Jia and Y. Zhao, Environ. Sci. Technol., 2017, 51, 3993-4000.

39 F. Ghanbari and M. Moradi, Chem. Eng. J., 2017, 102, 307315.

40 J. Fang, J. Li, L. Gao, X. Jiang, J. Zhang, A. Xu and X. Li, J. Colloid Interface Sci., 2017, 494, 185-193.

41 L. G. Devi, M. Srinivas and M. L. Arunakumari, Journal of Water Process Engineering, 2016, 13, 117-126.

42 Y. Feng, D. Wu, Y. Deng, T. Zhang and K. Shih, Environ. Sci. Technol., 2016, 50, 3119.

43 S. G. Kumar and K. S. R. K. Rao, Appl. Surf. Sci., 2015, 355, 939-958.

44 S. G. Kumar and K. S. Rao, Nanoscale, 2014, 6, 11574-11632. 45 J. Zhao, J. Nan, Z. Zhao, N. Li, J. Liu and F. Cui, Appl. Catal., $B, 2017,202,509-517$.

46 Y. Pang and H. Lei, Chem. Eng. J., 2016, 287, 585-592.

47 H. Li, S. Lee, Z. Wang, Y. Huang, W. Ho and L. Cui, Chem. Eng. J., 2017, 61-69.

48 X. Li, Z. Wang, B. Zhang, A. I. Rykov, M. A. Ahmed and J. Wang, Appl. Catal., B, 2016, 181, 788-799.

49 Y. Wang, X. Zhao, D. Cao, Y. Wang and Y. Zhu, Appl. Catal., $B, 2017,211,79-88$.

50 J. Liu, J. Zhou, Z. Ding, Z. Zhao, X. Xu and Z. Fang, Ultrason. Sonochem., 2017, 34, 953-959.

51 X. Feng, W. Li, L. Fang and D. Wang, J. Hazard. Mater., 2016, 308, 11.

52 S. G. Kumar and K. S. R. K. Rao, Appl. Surf. Sci., 2016, 391, 124-148.

53 L. Jie, Z. Zhao, P. Shao and F. Cui, Chem. Eng. J., 2015, 262, 854-861.

54 S. G. Kumar and K. S. R. K. Rao, RSC Adv., 2014, 5, 33063351.

55 P. Shao, X. Duan, J. Xu, J. Tian, W. Shi, S. Gao, M. Xu, F. Cui and S. Wang, J. Hazard. Mater., 2017, 322, 532-539.

56 T. Zhang, Y. Chen and T. O. Leiknes, Environ. Sci. Technol., 2016, 50, 5864-5873.

57 C. Gong, F. Chen, Q. Yang, K. Luo, F. Yao, S. Wang, X. Wang, J. Wu, X. Li and D. Wang, Chem. Eng. J., 2017, 321, 222-232. 58 L. Guo, Appl. Catal., B, 2010, 96, 162-168.

59 A. R. Amani-Ghadim, S. Alizadeh, F. Khodam and Z. Rezvani, J. Genet., 2015, 408, 60-68.

60 N. A. Zubir, C. Yacou, X. Zhang and J. C. D. D. Costa, J. Environ. Chem. Eng., 2014, 2, 1881-1888.

61 H. Li, J. Wan, Y. Ma, Y. Wang and M. Huang, Chem. Eng. J., 2014, 237, 487-496. 